\title{
Unexpected difficult extubation of double lumen bronchial intubation: a case report
}

\author{
Xingcai Zhang, Shumiao Tang, Zihui Lu and Yijun Chen ${ }^{*}$ (1)
}

\begin{abstract}
Background: The anesthetist and other members of the perioperative team need to be extremely cautious for successful completion of any surgery. If the final step of any general anesthetic-extubation is not sufficiently well planned, it can lead to critical airway incidents during the extubation and hinder transportation of the patient to the post-anesthesia care unit.

Case presentation: A 48-year-old female underwent video-assisted thoracoscopic surgery (VATS) combined with left lower lobectomy. The distal end of the left branch of the tracheal tube was lodged by surgical sutures. In this case, the respiratory physician burned the sutures using an argon electrode, after discussion with the thoracic surgery experts.

Conclusions: Teamwork is essential when caring for a patient with a shared airway. The anesthetist and surgeon must communicate well with each other to achieve optimal surgical outcomes. Importantly, testing the patency of the ETT prior to extubation should be a regular procedure, which is practical significance to guide safe extubation.
\end{abstract}

Keywords: Difficult extubation, Communication, VATS, Anaesthetic management

\section{Background}

Due to the COVID-19 epidemic, chest computed tomography $(\mathrm{CT})$ has become a routine screening method for most admitted patients, which has caused increasing number of lung nodules to be discovered. With advances in endoscopic, robotic and endovascular techniques, VATS can be performed in a minimally invasive way for managing most pulmonary, pleural and mediastinal diseases [1]. Thoracoscopic pulmonary nodule resection represents the most effective and suitable treatment for pulmonary nodules, and can provide essential histopathological information for definitive diagnosis, staging, and primary treatment [2]. Anesthetic management is essential for successful surgical management. Most thoracoscopic surgeries are performed under general anesthesia with double-lumen endotracheal intubation.

*Correspondence: 13967810490@139.com Department of Anesthesiology, Ningbo City First Hospital, No. 59 Liuting Street, Haishu District, Ningbo, Zhejiang, China
Extubation is an essential procedure in anesthesia and critical care medicine. Adverse events at the time of extubation account for a significant proportion of airway management-related serious adverse events [3]. Herein, we presented the case report of a patient whose extubation management was especially challenging.

\section{Case presentation}

A 48-year-old female, with height of $160 \mathrm{~cm}$ and weight of $55 \mathrm{~kg}$, was found to have a left lower lobe nodule in the lung and was scheduled for thoracoscopic wedge resection of the left lower lobe. The anesthesia was induced with $0.04 \mathrm{mg} / \mathrm{kg}$ of midazolam, $0.6 \mu \mathrm{g} / \mathrm{kg}$ of sufentanil, $2 \mathrm{mg} / \mathrm{kg}$ of propofol and $0.6 \mathrm{mg} / \mathrm{kg}$ of rocuronium. Then, a left $35 \mathrm{Fr}$ endobronchial tube (Covidien llc, USA) was successfully intubated at a depth of $28 \mathrm{~cm}$ to incisors. Fiberoptic bronchoscopy was used to confirm that there was no problem with the location of the tube after the posture of the patient was changed to the right lateral decubitus position. original author(s) and the source, provide a link to the Creative Commons licence, and indicate if changes were made. The images or other third party material in this article are included in the article's Creative Commons licence, unless indicated otherwise in a credit line to the material. If material is not included in the article's Creative Commons licence and your intended use is not permitted by statutory regulation or exceeds the permitted use, you will need to obtain permission directly from the copyright holder. To view a copy of this licence, visit http://creativecommons.org/licenses/by/4.0/. The Creative Commons Public Domain Dedication waiver (http://creativeco mmons.org/publicdomain/zero/1.0/) applies to the data made available in this article, unless otherwise stated in a credit line to the data. 


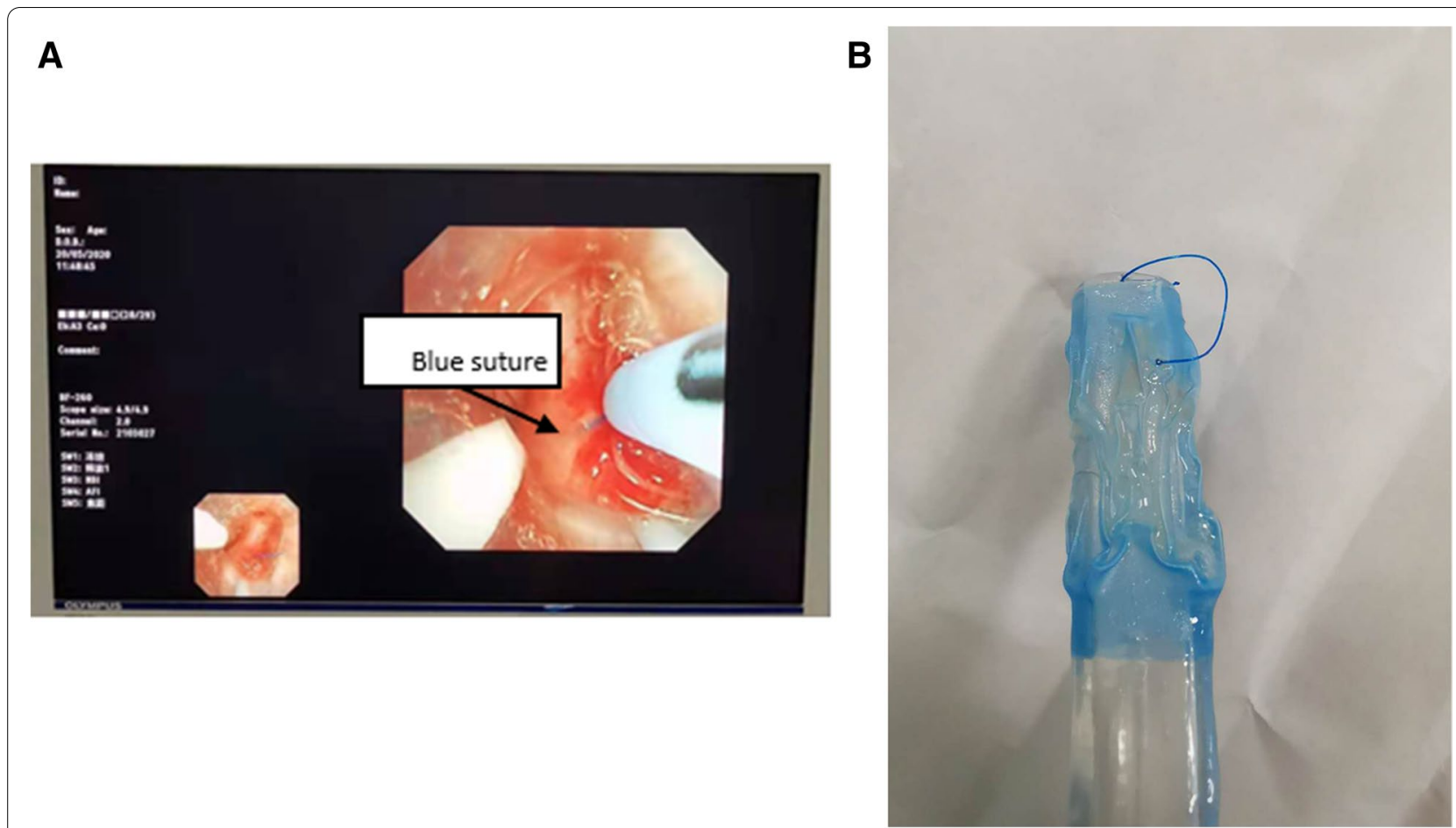

Fig. 1 A The fiberoptic bronchoscope revealed the surgical suture; B The suture stump after the tracheal tube was pulled out

Anesthesia was maintained with sevoflurane $1.5 \mathrm{vol} \%$, oxygen $2 \mathrm{~L} / \mathrm{min}$, remifentanil $250 \mathrm{mcg} / \mathrm{hr}$., $4 \mathrm{mg} / \mathrm{kg} / \mathrm{h}$ of propofol. The intraoperative pathological diagnosis of the excised mass was invasive adenocarcinoma. Subsequently, the patient underwent VATS combined with left lower lobectomy. The operation time was $1.5 \mathrm{~h}$ and the patient was transferred to post-anesthesia care unit (PACU) for decannulation. The patient recovered consciousness from anesthesia after $30 \mathrm{~min}$, exhibiting effective spontaneous ventilation and meeting extubation criteria. Unpredictably, the tracheal tube seemed to be mechanically constrained and we were unable to withdraw the endotracheal tube (ETT). We had to administer propofol and remifentanil intravenously for sedation and checked the airway with a fiberoptic bronchoscope, which revealed that the surgical suture of the bronchial membrane was inserted into the distal end of the left branch of the tracheal tube (Fig. 1A). Thereafter, we held detailed consultations with respiratory physicians and thoracic surgeons. The thoracic surgeon assured that breaking the suture will not cause adverse effects on the patient. It took only $1 \mathrm{~s}$ for the respiratory doctor to burn the sutures using an argon electrode (ERBE 20132-177) with the aid of fiberoptic bronchoscope. The mode of the argon electrode was strong electrocoagulation and the power was $35 \mathrm{~W}$. Finally, the bronchial tube was pulled out smoothly (Fig. 1B) and the patient was safely sent back to the ward after CT review, which showed no abnormalities. On the 1, 3, and 7 days after the operation, we followed-up the patient, and there were no related complications such as bronchial leak or bronchial rupture.

\section{Discussion and conclusions}

Extubation is an essential procedure in anesthesia. While safely performed in a large proportion of cases, it can present significant challenges and complications in rare cases [3]. Forceful extubation has been reported to cause vocal cord edema, dislocation of the arytenoid cartilage and laryngeal trauma, which was associated with fatality [4]. Difficulty in extubation due to mechanical issues in the ETT is not uncommon in clinical practice. Previously reported cases of lodged ETTs have been due to failure of cuff deflation, distorted laryngeal anatomy, manufacturing faults, entanglement with feeding tube and the balloon obstructed by a bite block [5]. Unrecognized subglottic stenosis or severe edema physically preventing removal of ETT has been reported [6], as well as an erroneously placed surgical stitch anchoring the ETT to the tracheal wall. Most of these cases have been reported in relation to head and neck surgical procedures [7]. As with our case, Bradley and Sprung reported an unusual case involving the accidental placement of a surgical 
suture through both the Carlens tube and pulmonary artery [8]. Unfortunately, forceful extubation resulted in massive hemorrhage from the severed pulmonary artery. However, we reported a more fortunate outcome in the current case.

In this case, we discussed in detail with the respiratory doctor and thoracic surgeons whether breaking the sutures would adversely affect the patient and how to break the sutures. Considering that the electrode might damage the tracheal tube, we chose the minimum power that could burn the sutures. Moreover, when the electrode was ready to work, it was necessary to stop the mechanical ventilation, which reduced the oxygen concentration to below $40 \%$.

The learnings from this case were as follows: first, the patient was scheduled for thoracoscopic wedge resection of the left lower lobe. Due to lack of communication with the surgeon in a timely and effective manner, we used 35 Fr left-side endobronchial tube intubation for lung isolation, which caused human interference. It is important to select an appropriate (non-surgical side) tracheal tube. Second, care must be taken even for patients not identified as being at risk of extubation. For example, in this case, pulling out the tracheal tube quickly could lead to the risk of bronchial rupture. Fiberoptic bronchoscopy, as "the third eye of anesthesiologists", played a clear diagnostic role. Third, the airway manager must be self-aware of potential human factor pitfalls to avoid. Multidisciplinary team training or rounds on adverse airway events might help to improve communication and cooperation for future difficult airway situations that involve multiple specialties.

In conclusion, although difficult decannulation of the airway is a complication seldom encountered, one should always be vigilant when resistance is noted during ETT removal.

\section{Abbreviations}

VATS: Video-assisted thoracoscopic surgery; CT: Chest computed tomography:" PACU: Post-anesthesia care unit; ETT: Endotracheal tube.

\section{Acknowledgements}

None.

\section{Authors' contributions}

CYJ collected all the patient initial data; ZXC drafted the manuscript; LZH and TSM completed the anesthesia management; All authors read and approved the final manuscript.

\section{Funding}

This case report was not funded by any funding.

\section{Availability of data and materials}

The datasets are available from the corresponding author on request.

\section{Declarations}

\section{Ethics approval and consent to participate}

This case report was approved by the Institutional Ethics Committee of Ningbo City First Hospital. The patient had signed the informed consent for this anesthesia procedure.

\section{Consent for publication}

Written informed consent was obtained from the patient for publication of this article and any accompanying images.

\section{Competing interests}

The authors declared that they have no competing interests.

Received: 23 September 2021 Accepted: 15 November 2021

Published online: 10 December 2021

\section{References}

1. Elsayed HH, Moharram AA. Tailored anaesthesia for thoracoscopic surgery promoting enhanced recovery: The state of the art. Anaesth Crit Care Pain Med. 2021;40:2-100846.

2. Zheng Y, Wang H, Ma X, Cheng Z, Cao W, Shao D. Comparison of the effect of ultrasound-guided thoracic paravertebral nerve block and intercostal nerve block for video-assisted thoracic surgery under spontaneous-ventilating anesthesia. Rev Assoc Med Bras (1992). 2020;66(4):452-7.

3. Parotto $M$, Cooper RM, Behringer EC. Extubation of the challenging or difficult airway. Curr Anesthesiol Rep. 2020;4:1-7.

4. Hulme J, Agarwal S. Failure to deflate an endotracheal cuff. Acta Anaesthesiol Scand. 2008;52:5-719.

5. Panda CK, Karim HMR. Too much of anything is bad: An unusual case of a stuck endotracheal tube with deflated cuff. Saudi J Anaesth. 2019:13(2):156-7.

6. Yazbek-Karam VG, Haswani RW, Karam HS, Haddad WM, Youssef PS, Hachem BF, et al. Unusual case of difficult double-lumen endotracheal tube removal. J Clin Anesth. 2009;21 (7):514-6.

7. Leong SL, Lin YT, Hsing CH, Lan KM, Lin MC. Unanticipated difficult nasotracheal extubation following oral surgery. Acta Anaesthesiol Taiwan. 2014;52(4):197-200.

8. Bradley D, Sprung J. An unusual cause of difficult tracheal extubation. J Cardiothorac Vasc Anesth. 2003;17(2):279-80.

\section{Publisher's Note}

Springer Nature remains neutral with regard to jurisdictional claims in published maps and institutional affiliations.

Ready to submit your research? Choose BMC and benefit from

- fast, convenient online submission

- thorough peer review by experienced researchers in your field

- rapid publication on acceptance

- support for research data, including large and complex data types

- gold Open Access which fosters wider collaboration and increased citations

- maximum visibility for your research: over 100M website views per year

At BMC, research is always in progress.

Learn more biomedcentral.com/submissions 